\title{
REVITALISASI PENGELOLAAN DAN PENYELENGGARAAN TRI DHARMA PERGURUAN TINGGI DIANTARA PERSIMPANGAN KEPENTINGAN ANTAR BANGSA
}

\author{
Yohan \\ Dosen Fakultas Tarbiyah IAIN SAS Bangka Belitung \\ yohan.nur.yahya@gmail.com
}

\begin{abstract}
Abstrak
Sejumlah akademisi mulai dari 'akademisi murni,' 'akademisi politis,' 'politisi akademis' hingga kalangan 'birokrat akademis' sedang berjibaku dalam menyikapi tuntutan internasionalisasi Pendidikan Tinggi yang sedang berkembang saat ini karena tekanan kepentingan dunia pendidikan global. Dengan semangat 'Liberasi Pendidikan' yang bersandar kepada Kesepakatan Umum dalam Perdagangan Pelayanan Jasa atau General Agreement on Trade in Services (GATS) yang terlahir dari rahim 'globalisasi industri' yang terikat oleh untaian jejaring motif-motif ekonomi dalam Organisasi Perdagangan Dunia atau yang disingkat WTO (World Trade Organization) menjadikan sejumlah negara besar sangat 'bergairah' untuk menginternasionalisasikan institusi Pendidikan Tinggi mereka ke sejumlah negara termasuk Indonesia. Sehingga muncul himbauan dari pemerintah agar segenap perguruan tinggi dalam negeri segera memprogramkan institusinya menjadi agent of economy development. Meskipun demikian, seberapapun besar desakannya dan seberagam apapun motif dan kepentingannya, revitalisasi harus diwujudkan berdasarkan tuntutan Tri Dharma Perguruan Tinggi sebagaimana yang diamanahkan oleh Pancasila, UUD 1945, UU, GBHN beserta segenap regulasi turunannya. Dari segudang potensi yang harus dioptimalkan, revitalisasi Sumber Daya Manusia-nya tetap harus menjadi yang utama agar 'kualitas energi ilmiah' tiap-tiap civitas akademika mampu mendongkrak etos kerja dalam aktifitas Tri Dharma sehingga bersesuaian dengan tuntutan zaman tanpa menciderai kepentingan rakyat. Oleh sebab itu, regenerasi Tri Dharma bukan hanya berfokus pada penguatan ekonomi semata namun juga 'nurani kemanusiannya' agar kreativitas dan inovasi kekinian menjadi relevan dengan pengelolaan sumber-sumber penghidupan di negeri khatulistiwa yang terdorong oleh kebijakan dan kebijaksanaan yang manusiawi, adil dan beradab. Akhirnya, jika Perguruan Tinggi Asing (PTA) lebih cenderung mengglobalisasikan 'sistem pendidikan dan risetnya' yang agak berbau 'kapitalisme' maka bangsa ini sudah sepantasnya lebih bercirikan Pendidikan Tinggi yang 'Rahmatan Lil'alamin' yang meninggikan harkat dan martabat bangsanya sendiri yang mampu memberikan perhatian dan kepedulian yang lebih mendalam kepada kegiatan pelayanan dan pengabdian sosial dan bukan hanya karena desakan globalisasi semata.
\end{abstract}

Kata Kunci: Kepentingan Global, Regenerasi, Revitalisasi, dan Tri Dharma Perguruan Tinggi 


\title{
Jurnal Ilmiah Sustainable
}

Vo. 1. No. 1, Juni 2018, 119-145

\begin{abstract}
At a recent time, a number of academics ranging from the 'practical and theoretical academics,' 'political academicians,' 'academic politicians' to 'academic bureaucrats' are encouragingly striving for responding to the demands of internationalization of Higher Education because of the pressure of global education interests. With the spirit of 'education liberation' relying on the General Agreement of Trade in Services (GATS) as a result of 'industrial globalization matrix' which is associated with economic motives initiated by the World Trade Organization (WTO) makes some developed countries enthusiastically promote their higher education institutions to a number of countries. Consequently, the invigoration of Indonesian government to all domestic universities to immediately program their institutions as the agents of economy development. Nonetheless, the implementation and management of Tri Dharma are not only specified on developing the strength of national economy but also on social conscience to make the current creativity and innovation can be more relevant to the need of subsistence resources development based on Indonesian characters and uniqueness driven by the moral sense of humanity, fairness and civilized policies. Therefore, the revitalization process should be accordingly manifested toward the principles of Tri Dharma of the university as mandated by Pancasila, Constitution of 1945, Law, GBHN and all of the derivative regulations, not strictly due to the insistence of global pressures. Thus, human resources must be the main agenda to revitalize among other potentials in generating and optimizing the ethic of scientific works in Tri Dharma activities in fulfilling the current necessitates without harming the interests of Indonesian populace. Finally, when Foreign Higher Education policies (FHE) are commercially inclined to globalize their education system and research which is relatively 'capitalism', thus our national higher education should be increasingly characterized by the humanity affectionate which elevates the dignity of Indonesia by providing serious devotions and concerns on social and community service.
\end{abstract}

Keywords: Global Interests, Implementation, Revitalization, Management, and Tri Dharma of Higher Education 


\section{Jurnal Ilmiah Sustainable}

Vo. 1. No. 1, Juni 2018, 119-145

\section{A. Pendahuluan}

Berawal dari semangat 'Liberasi Pendidikan' yang bersandar kepada Kesepakatan Umum pada Perdagangan Pelayanan Jasa atau General Agreement on Trade in Services (GATS) menjadikan sejumlah negara maju sangat 'bersyahwat' untuk meng-internasionalisasikan institusi Pendidikan Tinggi mereka ke sejumlah negara termasuk Indonesia.' Namun jika diselami lebih mendalam, nampaknya kesepakatan tersebut masih bersifat 'ke-abu-abuan.' Jika masih dalam bentuk jejaring kolaborasi yang bersifat 'internasionalisasi' maka setiap individu maupun kelompok, suku, bangsa, dan negara tentunya masih berkesempatan untuk memiliki dan berbuat secara mandiri sambil terus berkreasi dan berinovasi dalam kendali yang bersifat otonomi karena masih ada batas-batas yang jelas. Namun bagaimana jika sudah terkonsentrasi dalam bulatan globalisasi, maka siapakah yang akan menjadi pengontrol dan pemilik Pendidikan Tinggi di seantero dunia saat ini ${ }^{1}$ Bukan tidak mungkin suatu saat kelak dunia Pendidikan Tinggi akan masuk dalam daftar 'Bursa Saham' karena didukung oleh embel-embel aktualisasi konsep 'bisnis pendidikan' khususnya 'bisnis Pendidikan Tinggi alias 'bisnis jasa bidang pengajaran dan penelitian' yang berpusat pada satu negara hingga satu direksi kepemimpinan dengan pengelolaan yang bisa diperjualbelikan karena desakan globalisasi.

Melalui 'Kesepakatan Bersama' yang sudah terlanjur diijab-kabulkan tersebut, maka setahap demi setahap, terlebih saat ini, globalisasi Pendidikan Tinggi tersebut mulai mendesak lapisan pori-pori bangsa Indonesia yang mulai

${ }^{1}$ Dalam hal ini, "internasionalisasi' bisa dimaknai sebagai proses peningkatan kerjasama dan keterhubungan antar negara. Sedangkan 'globalisasi' dipahami sebagai proses integrasi antar negara (Beerkens, 2004)." Diterjemahkan dan diadaptasi dari Luijten-Lub, (2007). Berkenaan dengan bakal masuknya sejumlah Perguruan Tinggi Asing ke Indonesia, sebagai permulaan biasanya masih berbentuk kerjasama alias 'gandeng-gandengan' dengan perguruan tinggi dalam negeri khususnya perguruan tinggi dalam negeri yang berstatus swasta. Namun pertanyaannya, 'apakah mereka mau 'nebeng' terus dengan yang lebih kecil sedangkan perguruan tinggi mereka nota-benenya merupakan perguruan tinggi besar dengan reputasi kemandirian institusi yang tak bisa diragukan lagi?' Oleh sebab itu, bentuk kolaborasi yang akan disepakati diharapkan bukan hanya sekedar basa-basi-hanya pada 2 unsur saja yaitu (1) Pendidikan dan pengajaran dan (2) penelitian-melainkan harus benar-benar mencakup ketiga unsur pokok Tri Dharma peguruan tinggi sebagaimana umumnya yang berlaku di Indonesia. 


\section{Jurnal Ilmiah Sustainable}

Vo. 1. No. 1, Juni 2018, 119-145

merasa tak nyaman karena suhu anginnya terkadang terlalu panas dan terkadang pula terlalu dingin sehingga membuat 'organ-organ vital' dalam negara ini menjadi kurang stabil. Pada satu waktu menjadi demam panas tinggi dan pada waktu yang lain menggigil kedinginan. Kondisi tersebut kemudian memaksa bangsa ini untuk segera melakukan diagnosa, khususnya dalam bentuk diagnosa akademik dan pedagogis. Maka tak ayal lagi para 'peracik rasa' Pendidikan Tinggi tanah air 'dipaksa' secara rutin untuk melakukan 'silaturahmi ilmiah' yang seringkali beraroma 'buah campuran' antara rasa birokratis, akademis, agamis, politis, ekonomis, hingga bisnis. Bentuk 'silaturrahmi ilmiah' yang beraroma dan berasa 'buah campuran' tersebut salah satunya adalah Rapat Dengar Pendapat antara Panja Evaluasi Pendidikan Tinggi, Komisi X DPR RI dengan Kemenristekdikti RI yang dilaksanakan pada hari Selasa Tanggal 10 Juli 2017 untuk tahun sidang 2017-2018 yang intinya harus segera melakukan 'revitalisasi' Pendidikan Tinggi. Namun pertanyaannya adalah kemanakah sesungguhnya arah kebijakan revitalisasi Pendidikan Tinggi yang hendak diarahkan bagi segenap kampus di negeri ini sebagaimana yang diamanahkan oleh Dewan Perwakilan Rakyat Republik Indonesia kepada Menristekdikti tersebut? Apakah revitalisasi tersebut dibutuhkan karena desakan 'internasionalisasi' dan 'globalisasi' Pendidikan Tinggi dunia ataukah karena kepentingan seluruh komponen bangsa?

Belakangan ini, sejumlah kampus besar negara-negara asing hendak menjajal peluang dan tantangan pasar Pendidikan Tinggi di Indonesia. ${ }^{2}$ Jika

${ }^{2}$ Beberapa perguruan tinggi elit yang berancang-ancang mengepakkan sayapnya untuk meng-internasionalisasi dan berpotensi meng-globalisasi-kan pendidikan tingginya di Nusantara tersebut diantaranya yaitu Cambridge University yang berbasis di Inggris dengan pengaruhnya yang menggurita di sejumlah negara kemudian Melbourne University, Monash University, Central Queensland University, dan Queensland University dari Australia yang mulai mengaum membahana ke seantero dunia. Kelima perguruan tinggi papan atas tersebut merupakan sebagian kecil dari universitas ternama di dunia yang rencananya akan membuka cabangnya di Indonesia yang rencananya dimulai tahun 2018. Selain ketiga kampus tersebut diatas, beberapa kampus nge-top lainnya yang bakal beroperasi di tanah air yaitu Imperial College London yang berbasis di Inggris. Kemudian ada lagi yang namanya National Taiwan University sebagai salah satu kampus tetangga yang lokasinya tak seberapa jauh dari negara kita. Retrived pada tanggal 5 Juni 2018 dari http://tengokberita.com/cambridge-university-akan-buka-cabang-di-indonesiatahun-ini/30Januari/2018 dan https://www.kaskus.co.id/thread//yuk-intip-profil-kampus-asingyang-bakal-masuk-indonesia/2018. Dengan kehadiran beberapa perguruan tinggi tersebut tentunya akan mempertajam aroma persaingan yang sangat 'sengit' dan 'legit' dalam dunia 


\section{Jurnal Ilmiah Sustainable}

Vo. 1. No. 1, Juni 2018, 119-145

penulis kaji lebih mendalam mengapa sejumah negara khususnya yang beraroma 'Westernisasi' sangat bernafsu sekali mendesak Indonesia agar segera membuka kran dan memberikan akses operasional bagi kampus-kampus mereka, hemat penulis hal tersebut tiada lain dan tiada bukan karena mereka hendak mendominasi dunia Pendidikan Tinggi hingga dunia industri secara global melalui-selain motif finansial-penguasaan kolektivitas data. ${ }^{3}$ Hal tersebut sangat beralasan sekali sebab sesungguhnya tiada bisnis komersil di dunia ini yang lebih unggul, berkelas dan prestisius di-antara semua jenis bisnis melainkan 'bisnis keilmuan' alias 'bisnis data dan informasi' dengan dunia industri yang melibatkan sejumlah perusahaan besar. ${ }^{4}$ Melalui eksplorasi info dan data ilmiah yang masih tertimbun diantara lahan-lahan tidur yang ditumbuhi oleh rerimbunan semak-belukar di-antara sejumlah manusia lugu di hamparan negeri Khatulistiwa ini, tentunya mereka lebih berpotensi menyiasati segala macam teknik, taktik serta strategi dalam menguasai kehidupan. Bahkan dengan penguasaan data-data teknis tersebut maka merekapun akan menguasai dunia secara keseluruhan. Alasannya, jika penguasaan harta benda hanya bisa bertahan beberapa masa saja dengan dimensi yang terbatas, maka penguasaan

Pendidikan Tinggi di tanah air dalam bingkai 'bisnis Pendidikan Tinggi' hingga menuju 'industri Pendidikan' secara keseluruhan.

3 "Institusi Pendidikan Tinggi di Asia Tenggara, baik secara sadar maupun tidak sadar, berasosiasi ke negara-negara barat khususnya Amerika Serikat. Hal ini terefleksi melalui gaya pendidikan di universitas-universitasnya, pengadopsian tradisi yang berorientasi konsumen atau pangsa pasar sebagaimana yang terjadi dalam dunia pendidikan Barat dan menjadikan 'skala peningkatan pendaftar mahasiswa internasional' sebagai strategi utama dalam menginternasionalisasikan pendidikan mereka. Meskipun model diatas memiliki banyak keuntungan, namun ia seringkali dilakukan tanpa pertimbangan yang matang (mengabaikan: pen.) bagi eksistensi kearifan dalam konteks lokal." Sebagaimana yang penulis adaptasi dari Wong \& Wu dalam Palmer, et al, [eds.]. (2011, hal. 199).

${ }^{4}$ Intellectual property, demikian istilah ilmiah untuk lisensi komersial dalam transaksi info dan data yang kreatif dan inovatif dengan trademark sesuai tingkatannya masing-masing dan berafiliasi dengan dunia Pendidikan Tinggi global. Mengapa penulis menyatakan bahwa bisnis info dan data merupakan bisnis yang lebih unggul, berkelas dan prestisius di-antara semua jenis bisnis lainnya? Hal tersebut dikarenakan para pelakunya bukanlah orang sembarangan melainkan kalangan intelektual yang bertransaksi dengan kalangan industri dan koporasi bisnis, organisasi swasta maupun institusi pemerintah dengan istilah yang cukup keren yaitu scientific research invention. Untuk lebih jelasnya, lihat artikel-artikel ilmiah yang mengkaji seputar topik diatas, misalnya, Mirowski, P. \& Van Horn, R. (2005), Barirani, A. et al, (2017) dan Gueenhuizen, M. \& Soetanto, D. (2015) atau topik-topik lainnya yang sejenis. 


\section{Jurnal Ilmiah Sustainable}

Vo. 1. No. 1, Juni 2018, 119-145

ilmu dan teknologi akan mendominasi segalanya dengan rentang waktu yang sangat lama sekali.

Melalui laporan singkat Panja Evaluasi Pendidikan Tinggi, Komisi X DPR RI yang meminta Kemenristekdikti RI untuk melakukan revitalisasi Perguruan Tinggi, mulai dari sumber daya manusia, kelembagaan, sampai sarana dan prasarana berbasis Teknologi Informasi, dalam menghadapi era industri 4.0 sangat jelas bahwa arah sikap dan pandangan tersebut lebih berorientasi kepada penguatan ekonomi global. Bukan hanya itu, kesimpulan dan keputusan rapat tersebut pada ujung-ujungnya secara dominana lebih berorientasi untuk memperkuat bingkai-bingkai globalisasi industri. ${ }^{5}$ Begitulah konsep praktis dan pragmatis yang berseliweran dalam kepala para wakil rakyat di Komisi X DPR RI yang penulis istilahkan dengan sebutan komunitas 'politikus akademis' dalam negeri bagaimana mereka menyikapi perkembangan tuntutan internasionalisasi Pendidikan Tinggi saat ini karena tekanan kepentingan dunia pendidikan global yang melintasi antar bangsa dan negara. ${ }^{6}$ Lantas sekarang bagaimana dengan sikap dan pandangan anda sebagai pembaca dan penelaah segala bentuk kebijakan dan regulasi yang dilahirkan oleh pihak-pihak yang berwenang dalam me-revitalisasi dunia Pendidikan Tinggi di tanah air?

${ }^{5}$ Rapat Dengar Pendapat Komisi X DPR RI bersama jajaran Kemenristekdikti pada hari Selasa Tanggal 10 Juli 2017 dengan agenda pembahasan utama yaitu: (1) Sasaran Strategis Pendidikan Tinggi, (2) Kebijakan dan Target Pendidikan Tinggi, (3) Capaian dan Permasalahan Pendidikan Tinggi, dan (4) Tantangan Pendidikan Tinggi di Era Industri 4.0. Komisi X DPR RI bidang Pendidikan dan Kebudayaan, Pemuda dan Olahraga, Pariwisata, Ekonomi Kreatif, Ristek Dikti, dan Perpusnas. Tahun Sidang 2017-2018. Panja Evaluasi Pendidikan Tinggi Komisi X DPR RI 2017-2018.

6 'Globalisasi' berasal dari kata global dan lebih khususnya lagi yaitu globe yang artinya bulat atau bundar tanpa jurang pemisah alias penyekat. Dan globalisasi mesti bersifat total dan menyeluruh dengan satu titik komando. Oleh sebab itu, berkenaan dengan 'Globalisasi Pendidikan Tinggi,' maka ada beberapa hal yang mesti menjadi bahan pemikiran kita diantaranya yaitu bahwa "globalisasi merupakan energi pendorong yang paling efektif untuk mendorong perubahan dalam mengelola perguruan tinggi. Gagasan globalisasi merupakan jargon yang bersifat politis para politikus dunia yang berkepentingan penuh dalam menggagas konsepkonsep persaingan 'intelektualitas,' 'skill' dan 'superioritas' dengan alasan pentingnya persaingan kualitas melalui kepemimpinan dan pengelolaan perguruan tinggi yang berdaya saing dalam membentuk pendekatan-pendekatan terbaru dalam dunia pendidikan dan penelitian. Meskipun demikan sebenarnya tidak ada definisi yang bersifat universal dan berterima secara umum mengenai gagasan globalisasi ini. Namun yang pasti, dalam konteks kekinian, istilah ini secara umum dipahami sebagai bentuk perubahan yang komprehensif dalam bidang sosial dan ekonomi." Diterjemahkan dan diadaptasi dari Maringe \& Foskett (2010). 


\section{Jurnal Ilmiah Sustainable}

Vo. 1. No. 1, Juni 2018, 119-145

\section{B. Kebijakan Pendidikan Tinggi dalam Tekanan Arus Globalisasi}

Sebagaimana yang telah penulis singgung pada bagian pendahuluan mengenai hasil sidang tahunan 2017-2018 dalam rapat dengar pendapat yang bersifat terbuka yang mencakup empat agenda pembahasan yang meliputi (1) sasaran strategis Pendidikan Tinggi, (2) kebijakan dan target Pendidikan Tinggi, (3) capaian dan permasalahan Pendidikan Tinggi, dan (4) tantangan Pendidikan Tinggi di 'era industri 4.0. Keempat poin tersebut tentunya akan mewarnai gerak laju Pendidikan tinggi kita di kemudian hari. Maka dibawah ini penulis sampaikan beberapa hal menjadi bahan pertimbangan dalam revitalisasi pengelolaan dan penyelenggaraan Pendidikan Tinggi di tanah air di tengah arus kepentingan globalisasi yang berwarna-warni melalui sejumlah kebijakan yang sudah mengalami revisi demi revisi.

Dari hasil evaluasai tersebut, terdapat 5 kesimpulan penting dari Kemenristekdikti yang dapat dipaparkan kepada Panja Evaluasi Pendidikan Tinggi Komisi X DPR RI yang tentunya bukan hanya untuk para insan akademisi namun juga untuk seluruh bangsa Indonesia agar mereka dapat mengetahui sejauhmana peran dan kiprah Kemenristekdikti mengenai kondisi Pendidikan Tinggi di Indonesia sejak 2015 yang lalu hingga 2019 nanti. Ternyata hanya 'Sasaran Strategis' yang sudah melampaui pencapaian dari target yang telah diprogramkan oleh Kemenristekdikti RI untuk tahun 2017 untuk jangka waktu 2015 hingga 2019 nanti sebagaimana yang dapat dilihat pada tabel dibawah ini.

\section{Tabel 1}

Capaian Sasaran Strategis/Indikator Sasaran Strategis Kemenristek Dikti Tahun 2017

\begin{tabular}{|l|l|l|l|l|}
\hline \multirow{2}{*}{ SS/IKSS } & \multicolumn{2}{|c|}{2017} & Target & $\begin{array}{l}\text { Target } \\
2019\end{array}$ \\
\cline { 2 - 3 } & Target & Realisasi & 2018 & 2019 \\
\hline Indeks Inovasi & 16,85 & $48,56^{*}$ & 24,82 & 32,41 \\
\hline Indeks Pendidikan Tinggi & 26,17 & 39,86 & 34,12 & 42,25 \\
\hline Indeks Reformasi Birokrasi & 75 & 71,23 & 80 & 85 \\
\hline
\end{tabular}




\section{Jurnal Ilmiah Sustainable}

Vo. 1. No. 1, Juni 2018, 119-145

Hasil Rapat Dengar Pendapat Komisi X DPR RI bersama jajaran Kemenristekdikti pada hari Selasa Tanggal 10 Juli $2017^{7}$. *Masih dalam tahap proses review dan analisis.

Beberapa Indikator program pembelajaran dan kemahasiswaan dan program peningkatan Sumber Daya pada tahun 2017 yang belum mencapai target sebagaimana yang diharapkan bisa dilihat pada tabel dibawah ini.

\section{Tabel 2}

\section{Indikator Program Pembelajaran dan Kemahasiswaan dan Program}

Peningkatan Sumberdaya pada tahun 2017

\begin{tabular}{|l|l|c|c|}
\hline \multicolumn{1}{|c|}{ Program } & \multicolumn{1}{|c|}{ Indikator Program } & $\begin{array}{c}\text { Target } \\
\mathbf{2 0 1 7}\end{array}$ & $\begin{array}{c}\text { Realisasi } \\
2017\end{array}$ \\
\hline \begin{tabular}{l} 
Program $\begin{array}{l}\text { Pembelajaran dan } \\
\text { Kemahasiswaan }\end{array}$ \\
\cline { 2 - 4 }
\end{tabular} & $\begin{array}{l}\text { Lulusan bersertifikat Kompetensi dan } \\
\text { profesi }\end{array}$ & $65 \%$ & $55,07 \%$ \\
\cline { 2 - 4 } & Lulusan PT yang langsung bekerja & $65 \%$ & $63 \%$ \\
\cline { 2 - 4 } & PT yang menerapkan SN Dikti & $75 \%$ & $67,72 \%$ \\
\cline { 2 - 4 } & Mahasiswa yang lulus PPG & $96 \%$ & $67,13 \%$ \\
\hline Program & Jumlah SDM yang meningkat karirnya & 19.228 & 14.561 \\
\cline { 2 - 4 } $\begin{array}{l}\text { Peningkatan } \\
\text { Sumber Daya }\end{array}$ & SDM yang meningkat kompetensinya & 2.141 & 1.669 \\
\cline { 2 - 4 } & Jumlah revitalisasi Sarpras PTN & 118 & 1 \\
\hline
\end{tabular}

Sumber: Rapat Dengar Pendapat Komisi X DPR RI bersama jajaran Kemenristekdikti pada hari Selasa Tanggal 10 Juli $2017^{8}$

Kemudian untuk pengeluaran per-mahasiswa dibanding GDP Indonesia termasuk yang terendah dibandingkan dengan negara yang diteliti oleh OECD pada tahun 2015. Sehingga rapat dengar pendapat dalam sidang tahunan tersebut menghasilkan enam catatan penting terkait anggaran untuk Riset dan Pendidikan Tinggi. Keenam catatan penting tersebut yaitu:

“(1) menjadikan Perguruan Tinggi sebagai subjek kena pajak akan meningkatkan biaya pendidikan tinggi dan menghambat upaya peningkatan akses masyarakat ke pendidikan tinggi, (2) pembiayaan PNBP/BLU di PTN hanya berkisar antara $21 \%$ sampai $26 \%$, (3) pemanfaatan anggaran PNBP sebagian besar (kurang lebih 80\%) diperuntukkan bagi kebutuhan operasional Tri dharma PT dan sekitar 20\% untuk belanja modal, (4) ruang fiskal untuk beasiswa dosen dan investasi makin terbatas. Anggaran Rupiah

7 Panja Evaluasi Pendidikan Tinggi Komisi X DPR RI 2017-2018. Retrived on July 18, 2018 from http://www.dpr.go.id/dokakd/dokumen/pdf

${ }^{8}$ Panja Evaluasi Pendidikan Tinggi ...... 2017-2018 


\section{Jurnal Ilmiah Sustainable}

Vo. 1. No. 1, Juni 2018, 119-145

Murni untuk belanja pegawai mengalami kenaikan setiap tahunnya (tahun 2018 mencapai 56\% dari total Rupiah Murni), (5) anggaran penelitian yang bersumber dari PNBP diharapkan dapat mencapai $10 \%$ dan bersumber dari BLU diharapkan dapat mencapai 15\%, karena anggaran yang bersumber dari Rupiah Murni sangat tergantung dari besaran dana BOPTN, dan (6) pemanfaatan anggaran BLU untuk gaji dan tunjangan rata-rata sebesar 31\% karena BLU harus membayar remunerasi dan tidak dibayarkan dari Rupiah Murni." 9

Sedangkan upaya yang harus dilakukan dalam pelaksanaan reformasi birokrasi ada empat poin yaitu:

“(1) penerbitan Permenristekdikti No. 54 Tahun 2016 tentang tata nilai, budaya kerja, dan kode etik pegawai di lingkungan Kemenristekdikti RI, (2) pembentukan Sistem Informasi Monitoring dan Evaluasi (SiMonev), (3) peningkatan Pelayanan kepada masyarakat melalui Quick Wins berupa "Pembentukan Unit Layanan Terpadu," dan (4) mewajibkan setiap PTN dan Kopertis melaksanakan reformasi birokrasi dengan membentuk Tim RB PTN/Kopertis, membuat Peta Jalan PTN/Kopertis dan menentukaan Quick Wins." 10

Selanjutnya Strategi Kemenristekdikti dalam menghadapi Era Industri 4.0 dan era Disrupsi mencakup tujuh rekomendasi. Adapun ketujuh rekomendasi yang harus ditindaklanjuti tersebut yaitu:

“(1) penyelarasana paradigma Tri Dharma Perguruan Tinggi dengan 'era industri 4.0,' (2) penerapan Pendidikan Jarak Jauh (PJJ) berbasis hybrid/blended learning/online melalui format baru sistem pembelajaran Cyber University, (3) komitmen peningkatan investasi di sektor pengembangan digital skill, (4) selalu mencoba dan menerapkan prototype teknologi terbaru (learning by doing), (5) menggali bentuk kolaborasi baru bagi model sertifikasi atau pendidikan dalam ranah peningkatan digital skill, (6) memperkuat kolaborasi antara dunia industri, akademisi, dan masyarakat untuk mengidentifikasi permintaan dan ketersediaan skill bagi era digital masa depan, dan (7) menyusun

\footnotetext{
${ }^{9}$ Panja Evaluasi Pendidikan Tinggi ...... 2017-2018

10 Panja Evaluasi Pendidikan Tinggi ...... 2017-2018
} 


\section{Jurnal Ilmiah Sustainable}

\section{Vo. 1. No. 1, Juni 2018, 119-145}

kurikulum pendidikan (reorientasi kurikulum) dengan memasukkan materi terkait human digital skill."11

Berangkat dari hasil dengar pendapat dengan jajaran Kemenristekdikti tersebut diatas, maka Panja Evaluasi Dikti Komisi X DPR RI memberikan beberapa sikap dan pandangan baik secara langsung maupun tidak langsung yang menyiratkan beberapa poin kebijakan yang terekomendasi dari para wakil rakyat yang harus segera diimplementasikan oleh pemerintah yang dalam hal ini berada dalam wewenang Kemenristek Dikti untuk:

"(1) meninjau ulang dan melakukan sinkronisasi setiap paparan yang disampaikan supaya konsisten dan komprehensif sebagai bahan yang tak terpisahkan mulai dari penyusunan laporan, kesimpulan dan rekomendasi Panja Evaluasi Dikti Komisi X DPR RI, (2) melakukan langkah-langkah strategis terhadap sasaran strategis yang telah ditetapkan namun belum tercapai serta mampu menjawab permasalahan yang telah teridentifikasi, (3) melakukan koordinasi dengan Kemenkeu RI maupun BAPENAS RI terkait antara lain mengenai peningkatan alokasi anggaran Ristek dan Dikti dan pajak Pendidikan Tinggi, (4) memperbarui panduan kurikulum Pendidikan Tinggi untuk semua jenis pendidikan tinggi (Pendidikan Akademik, Profesi dan Vokasi), dan (5) me-revitalisasi Perguruan Tinggi, mulai dari sumber daya manusia, kelembagaan, sampai sarana dan prasarana yang berbasis Teknologi Informasi dalam menghadapi era industri 4.0. ${ }^{12 "}$

Dari kelima poin sikap dan pandangan tersebut diatas menyiratkan semacam kebijakan untuk segera ditindaklanjuti, diselesaikan dan disempurnakan. Sehingga pertanyaannya adalah apakah para wakil rakyat tersebut telah memberikan sikap dan pandangan yang benar-benar komprehensif dan integratif? Dan sebaliknya apakah para Kemenristek Dikti benar-benar mampu mencerna kemudian memaknainya dan dengan sungguhsungguh untuk kemudian mengeksekusinya? Melalui beberapa poin sikap dan pandangan para wakil rakyat yang berkemungkinan multi-tafsir tersebut maka penulis mencoba menginterpretasinya melalui sudut pandang tertentu sebagaimana yang akan penulis bahasa pada bagian selanjutnya.

\footnotetext{
${ }^{11}$ Panja Evaluasi Pendidikan Tinggi ...... 2017-2018

12 Panja Evaluasi Pendidikan Tinggi ...... 2017-2018
} 


\section{Jurnal Ilmiah Sustainable}

Vo. 1. No. 1, Juni 2018, 119-145

Umumnya sejumlah kebijakan Pendidikan Tinggi di beberapa negara khususnya negara-negara dunia ketiga, Indonesia misalnya, terjadi karena terdesak oleh beragam stimulus dan kepentingan hingga tersedak-sedak oleh tekanan motivasi internasionalisasi dan liberasi dunia pendidikan yang terlahir dari rahim 'globalisasi industri' sebagai bagian dari jejaring motif-motif ekonomi dalam Organisasi Perdagangan Dunia atau yang lebih keren disingkat WTO. ${ }^{13}$ Ingat, WTO (World Trade Organization) bukan OPD apalagi TKO. Sebegitu kuatnya pengaruh organisasi ini hingga kemudian tercetuslah istilah-istilah dan teori-teori baru oleh para intelektual dunia yang berjiwa entrepreneurship, misalnya 'Bisnis Pendidikan' atau 'Bisnis Jasa Pendidikan' yang terbungkus dalam parsel besar yang berlabel 'pertumbuhan ekonomi.'14 Sehingga segenap

13 “Proses 'internasionalisasi pendidikan tinggi' terdorong melalui semangat liberalisasi pangsa pasar pendidikan melalui inisiatif Organisasi Perdagangan Dunia atau World Trade Organisation (WTO), secara lebih khusus didasarkan oleh Kesepakatan Umum pada Perdagangan Pelayanan Jasa atau General Agreement on Trade in Services (GATS)," sebagaimana yang dinyatakan oleh Van Vugh et al., (2002). Diterjemahkan dan diadaptasi dari Luijten-Lub, (2007, hal. 104). Untuk lebih jelasnya coba kita perhatikan pernyataan Taylor (2010) yang penulis kutip dalam bahasa aslinya, "Globalization is widely recognized as one of the most powerful forces for change in higher education. The term 'globalization' is commonly used by politician keen to encourage ideas of competition and perceptions of international excellence, and by university leaders looking to foster new approaches to teaching and research. Yet there is no universally accepted definition of the term and it is widely used as a shorthand collective for a wide range of different forms of economic and social change," dalam Maringe \& Foskett (2010), [eds \& conts]. Melalui pernyataan diatas, ada beberapa kata kunci dan prasa penting untuk kita simak dan maknai kembali yaitu "powerful forces for change, politicians, foster new approaches to teaching and research, no universal acceptable definition for higher education globalization, dan economic and social change." Dari beberapa kata kunci dan prasa tersebut, krusial untuk disimak, tidak ada satupun yang menyentuh isu-isu seputar formulasi pelayanan dan pengabdian kepada masyarakat. Kenapa demikian? Sebab globalisasi 'Pendidikan' dan 'Riset' yang berpotensi dikomersilkan dengan keuntungan finansial sedangkan 'pengabdian masyarakat' justeru sebaliknya, bisa-bisa menguras pundi-pundi harta benda institusi yang bersangkutan. Bisa-bisa ketika pulang ke negaranya masing-masing hanya menjinjing koper dan tiket pesawatnya belaka?

14 "Indonesia merupakan salah satu pasar utama Asia Tenggara dan fokus utama pembangunannya bertujuan untuk membangun kekuatan sosial beserta ekonomi dengan human capital yang berkembang secara fundamental. Sekalipun wilayahnya tersebar dalam cakupan yang cukup luas yang membatasi akses pendidikan berkualitas bagi kebanyakan penduduknya namun Indonesia telah membuat kemajuan yang cukup mengesankan di beberapa front misalnya sejak terjadinya krisis di Asia tahun 1997 hingga 1998 pada sektor Pendidikan Dasar. Beberapa tantangan berikutnya termasuk peningkatan layanan dan minat pendaftar sekolah menengah hingga perguruan tinggi, kualitasnya juga meningkat secara signifikan, sehingga 


\section{Jurnal Ilmiah Sustainable}

Vo. 1. No. 1, Juni 2018, 119-145

Perguruan Tinggi dihimbau untuk memprogramkan satu misi besar bagaimana menjadi institusi beserta alumninya tersebut sebagai agent of economy development. ${ }^{15}$ Dan secara lebih khusus lagi bagaimana perguruan tinggi mampu menjalankan roda Tri Dharma Perguruan Tinggi sambil berdagang dan juga mampu menciptakan para pedagang atau pencipta lapangan perdagangan alias pencipta lapangan perkerjaan (oleh alumni) dengan beragam bentuk dan aktifitasnya sebagai penggerak ekonomi masyarakat. ${ }^{16}$ Sepanjang hemat penulis, hal tersebut boleh-boleh saja untuk ditindaklanjuti asalkan kepentingan bangsa dan negara tetap terjaga dengan baik.

Dari hasil evaluasi tersebut diatas, sekarang kita tinggal menunggu hasil evaluasi selanjutnya untuk tahun 2018-2019 sambil menyelesaikan segenap program yang belum tuntas sebagaimana yang dipaparkan diatas kemudian mengantisipasi segala kemungkinan yang bakal muncul pada tahun-tahun mendatang. Bagaimana pencapaian target yang telah diprogramkan untuk tahun 2018 ini hingga 2019 nanti tentunya sangat diharapkan bisa memberikan hasil review yang lebih baik lagi dari tahun-tahun sebelumnya.

menjadikan pengelolaan dan perkembangan finansial-nya semakin responsif." Diterjemahkan dan diadaptasi dari OECD/Asian Development Bank (2015, hal. 3).

15 Sambutan Menteri Riset, Teknologi, dan Pendidikan Tinggi pada Upacara Peringatan Hari Pendidikan Nasional Tahun 2017 dengan tema "Peningkatan Relevansi Pendidikan Tinggi untuk Mendukung Pertumbuhan Ekonomi." Diantara poin penting yang telah disampaikan yaitu meminta perguruan tinggi agar lebih mampu memerankan dirinya sebagai agent of economic development disamping agent of education dan agent of research and development. Retrieved on July 18, 2018 from http://www.kopertis12.or.id/wp-content/uploads/2017/04/sambutanhardiknas-2017.pdf.

${ }^{16}$ Sah-sah saja jika ada perguruan Tinggi yang mau dan mampu menjadikan dirinya sebagai 'sentra penggerak pertumbuhan ekonomi' namun dengan catatan 'keuntungannya' secara nyata dikembalikan lagi untuk masyarakat bukan untuk kepentingan individu dan kelompok tertentu. Hal tersebut dikarenakan sesungguhnya Peguruan tinggi merupakan salah satu bentuk Non-Profit Organization. Artinya, pengelolaan dan pengembangan modal serta pengerukan kekayaan dari para nasabah (users) untuk mencapai 'keuntungan komersil' bukanlah menjadi tujuan dalam pendirian dan pengelolaannya baik yang berstatus swasta maupun negeri. Hal tersebut tertuang dalam Peraturan Pemerintah Republik Indonesia Nomor 4 Tahun 2014 tentang Penyelenggaraan Pendidikan Tinggi dan Pengelolaan Perguruan Tinggi pada Bagian 3 Pasal 8 Poin 1 dan 2 berbunyi: “(1) PTN didirikan oleh Pemerintah. (2) PTS didirikan oleh masyarakat dengan membentuk Badan Penyelenggara berbadan hukum yang 'berprinsip nirlaba' dan wajib memperoleh izin dari Menteri. 


\section{Jurnal Ilmiah Sustainable}

Vo. 1. No. 1, Juni 2018, 119-145

\section{Revitalisasi Tri Dharma di tengah-tengah Pusaran Motivasi antar Kepentingan}

Beberapa poin sikap para wakil rakyat terhadap kinerja Kemenristek Dikti beberapa tahun belakangan sebagaimana yang telah disinggung sebelumnya, tentu saja hal tersebut menjadi pekerjaan besar kedepan yang harus segera diselesaikan dan disempurnakan dalam menyambut, mengimbangi dan mengendalikan tekanan arus internasionalisasi hingga kepada kemungkinan globalisasi Pendidikan Tinggi diantara kepungan perguruan tinggi-perguruan tinggi raksasa dunia. Peran serta kita sebagai bagian dari insan akademisi tentunya sangat dibutuhkan untuk membantu Kemenristek Dikti dengan visi, misi dan program kerjanya maupun Komisi X DPR RI dengan fungsi, kewenangan dan 'kepentingan-kepentingan politiknya' maupun secara umum seluruh rakyat Indonesia dengan segala cita-cita, impian dan harapannya dalam mengamankan Pendidikan Tinggi di tanah air agar tetap kokoh dan adaptif dalam menghadapi segala kemungkinan perkembangan jaman.

Revitalisasi Tri Dharma perguruan tinggi bukanlah perkara yang mudah untuk diselami. Segenap komponen harus berani menyelam lebih dalam lagi agar mampu menemukan sumber-sumber energi penggerak Tri Dharma yang bertenaga tinggi dengan-bukan hanya kecerdasan tapi juga keberaniankecermatan strategi dan kekuatan finansial yang memadai untuk menyentuh dasar 'samudera peradaban ilmiah' kemudian diformulasikan menjadi sesuatu yang bernilai hingga mampu menciptakan perguruan tinggi-perguruan tinggi berkelas dunia. ${ }^{17}$ Oleh sebab itu kita memang perlu untuk selalu 'mengevaluasi' dan kemudian 'me-restorasi' nilai dan tujuan dasar pengelolaan dan penyelenggaraan Tri Dharma perguruan tinggi agar senantiasa bersesuaian dengan tuntutan zaman.

17 Universitas-Universitas kelas dunia yang tertera dalam University Ranking atau League tables tersebut bisa kita lihat misalnya di Website Times Higher Education (THE) World University Rankings dan QS World University Rankings atau yang lainnya. Namun menurut Brown (2006, hal. 38) bahwa "perengkingan tersebut dihasilkan melalui proses 'komersialisasi' yang hanya mengukur sisi kualitas pengajaran dan penelitian. Data-data perengkingan tersebut, walaupun dianggap ilmiah, ternyata masih tetap questionable. Sehingga kesannya perguruan tinggi dirangkingkan hanya sebagai produk semacam komoditas yang dikonsumsi ketimbang sebagai kesempatan untuk menambah pengetahuan dan pengalaman hidup." Diterjemahkan dan diadaptasi dari Longden dalam Teichler, et al (2011, hal 73-74) Selaras dengan hal tersebut, penulispun bertanya-tanya, "mengapa unsur 'Pengabdian Masyarakat (social service)' tidak menjadi ukuran? Apakah karena ia kurang atau sama sekali tidak bernilai komersil? 


\section{Jurnal Ilmiah Sustainable}

Vo. 1. No. 1, Juni 2018, 119-145

\section{Evaluasi Kebijakan Tri Dharma Perguruan Tinggi dalam Negeri}

Jika kita mengamati timbunan persoalan yang sedang dihadapi oleh Pendidikan Tinggi tanah air, maka evaluasi yang harus dilakukan tidak memungkinkan lagi menggunakan cara-cara grosiran melainkan harus menggunakan sistem borongan sebab terlalu banyak yang harus di-review ulang sehingga membutuhkan 'reformasi' berkelanjutan. ${ }^{18}$ Mulai dari etos kerja hingga kepraktisan sistem birokrasi yang belum memadai menjadikan gerak-laju Tri Dharma perguruan tinggi kita masih nampak terseok-seok kepayahan. Kemudian, ruang fiskal dan perpajakan yang masih sempoyongan hingga berdampak kepada program pembelajaran dan aktifitas kemahasiswaan yang tentunya pada ujung-ujungnya berpotensi menghambat peningkatan kualitas Sumber Daya civitas akademikanya yang tentunya beban beratnya juga harus ditanggung oleh masyarakat secara luas.

Belum lagi beban berat dalam menghadapi era industri yang menuntut Perguruan Tinggi tanah air untuk menata dan menghidupkan kembali ruh Tri Dharma perguruan tinggi yang dalam kontes nyata hingga kompetisi paragmatis dunia global saat ini. Bahkan demi menyesuaikan diri dengan desakan dunia Pendidikan Tinggi global, masalah teknologi komunikasi dan informasi juga masih menjadi semacam bengkel magang dunia maya, utak-atik sana dan utak-atik sini, gonta-ganti yang itu dan gonta-ganti yang ini, dalam proses penerapan cyber university yang berbasis digital skill mulai untuk kepentingan 'sertifikasi,' sistem informasi monitoring dan evaluasi hingga penerapan prototype teknologi terbaru yang bersifat teknis dan praktis agar rajutan kolaborasi antara dunia industri, akademisi

18 "Dukungan revitalisasi Pendidikan Tinggi, khususnya di Perguruan Tinggi Islam, secara eksplisit pernah dilakukan pada zaman orde baru dibawah kepemimpinan Presiden Soeharto dengan mengirim sejumlah mahasiswa untuk mengambil program doktoral ke negara-negara Barat untuk menghapus sistem doktrinisasi dalam dunia pendidikan di tanah air menuju pendekatan-pendekatan yang lebih kritis dan inkuisitif (berdasarkan riset) yang bukan hanya sedekar berfokus pada bidang keagamaan saja," sebagaimana yang dinyatakan oleh Luken-Bull (2013, hal. 13 \& 15). Kemudian terjadi lagi perkembangan berikutnya dari pendidikan dan pengajaran yang bersifat normatif menuju tataran akademik dan pedagogis yang lebih kontekstual, praktis dan teknis setelah tibanya masa reformasi hingga saat ini. 


\section{Jurnal Ilmiah Sustainable}

\section{Vo. 1. No. 1, Juni 2018, 119-145}

dan masyarakat secara umum dapat berjalan dan berkembang secara lebih efektif dan efesien. Sehingga urgensi revitalisasi pengelolaan dan penyelenggaraan Pendidikan Tinggi melalui kelima sikap dan pandangan Komisi X DPR RI terhadap laporan Kemenristek Dikti sebagaimana yang telah disampaikan pada bagian sebelumnya menjadi hal yang penting pula bagi penulis untuk disikapi kembali yang esensinya terletak pada pentingnya usaha revitalisasi dari sejumlah komponen yang telah dievaluasi sebagaimana yang akan penulis sampaikan dibawah ini.

Perlunya peninjauan ulang setiap paparan yang disampaikan supaya lebih konsisten dan komprehensif sebagai bahan yang tak terpisahkan dari penyusunan laporan dan melakukan sinkronisasi terhadap kesimpulan dan rekomendasi Panja Evaluasi Dikti Komisi X DPR RI." Artinya, paparan yang disampaikan belum konsisten dan komprehensif sehingga perlu adanya sinkronisasi antara kesimpulan laporan dan rekomendasi yang diberikan oleh Panja Evaluasi Dikti Komisi X DPR RI. Sehingga ketidak-konsistenan dan ketidak-sinkronisasian hingga belum komprehensifnya antara laporan, kesimpulan dan rekomendasi menyebakan hal tersebut menjadi persoalan tersendiri.

Dikarenakan sasaran strategis belum tercapai secara memadai, nampaknya Kemenristekdikti belum benar-benar menerapkan atau mungkin saja belum menemukan jurus-jurus terbaiknya agar bisa melangkah lebih terencana, taktis dan praktis yang mampu memberikan jawaban serta hasil yang lebih kalkulatif untuk mengembangkan Pendidikan Tinggi dalam negeri. Selanjutnya berkemungkinan Kemenristekdikti RI belum melakukan koordinasi yang intensif dengan Kemenkeu RI maupun BAPENAS RI-masalah ruang gerak fiskal-sehingga masih menyisakan persoalan kekurangan atau mungkin kesalah-pengelolaan alokasi anggaran serta perpajakan dalam Pendidikan tinggi sehingga mesti dikoordinasikan kembali. Oleh karena itu agar hasilnya bisa menjadi lebih logis lagi maka intensitas koordinasi kerja lintas dinas dan Lembaga harus diperkuat lagi.

Karena tekanan kepentingan dunia Pendidikan Tinggi global menyebabkan Pendidikan Tinggi (Pendidikan Akademik, Profesi dan Vokasi) kita seolah-olah sampai detik ini belum menemukan wajah tercantiknya namun selalu saja belepotan make-up dan lipstick yang tak berkesudahan 


\section{Jurnal Ilmiah Sustainable}

Vo. 1. No. 1, Juni 2018, 119-145

untuk dipoles lalu ditisukan kembali karena diencerkan oleh butiran keringat panas-dingin akibat pengaruh suhu globalisasi industri yang mulai meninggi sambil cengar-cengir antara cemas, resah dan gelisah hingga 'ke-pede-an' dan kegerahan. Akibatnya, pembaharuan kurikulum yang sudah dilakukan berulang-ulang bukan malah menjadi pola dan format yang lebih baru lagi melainkan mengulangi 'keresahan peserta didik' yang tak berkesudahan. Oleh sebab itu, memungkinkah jika kita harus berintegrasi dengan kurikulum yang digaung-gaungkan oleh banyak orang dengan sebutan International school curriculum ${ }^{19}{ }^{19}$ ni menunjukkan bahwa wajah kurikulum Pendidikan di negara kita memang tak pernah ada kata ending-nya untuk disalonkan kembali atau mungkin saja harus 'dioperasi plastik.'

Nah, ini yang menarik, Panja Evaluasi Dikti Komisi X DPR RI meminta Kemenristekdikti RI untuk melakukan revitalisasi Perguruan Tinggi mulai dari Sumber Daya Manusianya, kelembagaannya, sampai sarana dan prasarananya yang berbasis teknologi informasi dalam menghadapi 'era industri 4.0.' Itu artinya, pertama, perlunya revitalisasi terhadap manusiamanusia yang terlibat dalam dunia pendidikan tinggi kita berikut lembaganya, sarana dan prasarananya beserta kelengkapan teknologi informasinya dikarenakan semuanya belum berdaya alias masih impoten sehingga perlu di-revitalisasi. Jikalau pembaca tidak sepakat dengan pemaknaan pertama, kita gunakan pemaknaan yang kedua yaitu mengembalikan segalanya kepada esensi yang bersifat fundamental. Artinya, berkemungkinan selama ini para penggiat dan pelaku Pendidikan Tinggi tanah air masih main-main dalam mengelola dan menyelenggarakan perguruan tinggi bagaikan seorang anak laki-laki yang menarik-ulur tali layang-layang sambil kerepotan berlari kesana-kemari dengan nafas yang ngos-ngosan karena dipermainkan oleh gerak dan arus angin yang sulit terbaca serta kasat mata, atau bagaikan seorang anak kecil yang sedang menombol remote control mobil-mobil mainannya yang terkadang dilempar

19 "Ketika kita memilih untuk mengajar melalui cara tertentu (misalnya dalam bentuk kurikulum dan desain pembelajaran) di dalam kelas, artinya kita mengikuti yang namanya teori atau model yang bersifat personal atau orang per-orang. Hal ini barangkali memang nampak kasat mata ketimbang nyata namun inilah faktanya." Demikian pendapat Marsh (2009, hal. 23) yang penulis adaptasi dari Ledger, et al. (2009, hal. 8 ). 


\section{Jurnal Ilmiah Sustainable}

Vo. 1. No. 1, Juni 2018, 119-145

dan dibanting karena kecewa dan marah sebab mobil mainannya sering ngadat.

Sehingga, kaitan dengan metaporis diatas, dikarenakan masih terlalu polos atau mungkin juga karena belum dewasa dan belum pandai betul dalam menghargai dan memulyakan setiap jengkal esensi pengelolaan dan penyelenggaraan Pendidikan Tinggi maka perlu dilakukan revitalisasi agar tersadarkan kembali untuk memberikan perhatian yang benar-benar serius terhadap perencanaan, pengelolaan, penyelenggaraan, dan pengawasannya dengan sepenuh jiwa dan raga. Atau barangkali para pembaca lebih tertarik dengan pemaknaan yang ketiga yaitu revitalisasi dalam artian kembali lagi ke tuntutan awal yang berifat mendasar atau prinsip-prinsip pokok dalam pengelolaan dan penyelenggaraan Pendidikan Tinggi. Itu artinya segenap komponen dan perangkat yang menyusun bangunan Pendidikan Tinggi kita sudah keluar dari pondasi dasarnya atau sudah lepas terbawa angin badai globalisasi hingga terbang mengawang ke 'khayangan' hingga lupa diri, lupa ingatan, lupa daratan bahkan hilang kesadaran, entah itu karena kerasukan setan ataukah karena mabuk kepayang, akibat 'gurauan' dan 'bualan' globalisasi sehingga melupakan prinsip dasar sebagaimana yang diamanahkan oleh UU, UUD 1945 dan juga Pancasila beserta segala bentuk regulasi turunannya sebagai dasar pijakan dalam membangun dan mengembangkan Pendidikan Tinggi.

Kelanjutan dari sikap para wakil rakyat tersebut diatas yaitu pentingnya revitalisasi pendidikan tinggi berbasis teknologi informasi dalam menghadapi era Industri 4.0, maka pertanyaannya adalah bagaimana mungkin teknologi informasi Pendidikan Tinggi kita harus di-revitalisasi? Apanya yang harus di-revitalisasi, sedangkan kita baru saja mau memulainya ${ }^{20}$ Kemudian poin yang terakhir yaitu kata kunci 'era industri 4.0.' Betul bahwa dunia saat ini berada dalam pusaran arus globalisasi industri. Namun apakah kita harus menjadi cemas dan latah dengan jargon tersebut? Apakah segalanya mesti di-industrialisasikan? Jika dilihat dari letak

${ }^{20}$ Kita memang perlu berfokus pada isu-isu penting seputar reformasi pendidikan yang berkelanjutan; apakah dalam bentuk budaya belajar yang sesungguhnya dan transformasi pendidikan yang bercirikan kebijaksanaan, semangat dan kesepahaman antar budaya menjadi satu realita ataukah hanya sekedar retorika belaka (Zajda: 2015, hal. 160). 


\section{Jurnal Ilmiah Sustainable}

Vo. 1. No. 1, Juni 2018, 119-145

geografis, bukankah negara kita ini lebih bercorak dan lebih cocok jika berfokus pada dunia agro-industri dan industri kemaritiman? Ah sudahlah, pokoknya direvitalisasi sajalah! Siapa tahu saja memang benar adanya bahwa Pendidikan Tinggi kita memang masih mandul (impoten) atau menjadi mandul (impoten) gara-gara terlalu lama dikebiri dan dikomersialisasi oleh para penggiat kolonialisasi, politisasi dan ekonomisasi global sejak zaman 'Syekh Siti Jenar' dahulu kala hingga jamannya 'Siti Badriah' yang mulai eksis bersama sederetan para 'Pedangdut' dan 'Penggoyang Pantura.' Sehingga pertanyaan yang muncul lagi adalah apakah sikap dan pandangan yang diberikan oleh para wakil rakyat tersebut sudah benar-benar meng-cover seluruh tuntutan Tri Dharma Perguruan Tinggi sebagaimana yang diamanahkan oleh Pancasila, GBHN, Undang-Undang, dan UUD 1945?

\section{b. Revitalisasi Civitas Akademika Perguruan Tinggi}

Perlunya revitalisasi Tri Dharma Perguruan Tinggi di tengah-tengah motivasi antar kepentingan memang nampak berpelangi. Sebaliknya, secara global desakan 'internasionalisasi Pendidikan Tinggi'-walaupun agak sedikit eksklusif-nampak semakin menjadi-jadi sesuai motif dan arahnya sendirisendiri. Sehingga untuk mewujudkan 'suksesi' dalam me-revitalisasi civitas akademika' di perguruan tinggi dalam negeri membutuhkan adaptasi di sana-sini.

Untuk urusan non-human resources misalnya, tentu sudah jelas, tidak akan ada sikap dan perilaku resistensi apalagi anti revitalisasi karena segalanya bisa di-restrukturisasi, diadaptasi dan ditata ulang hingga direstorasi kembali. Namun bagaimana dengan manusianya? Apakah segenap insan 'akademisi murni' maupun 'akademisi politis' hingga kepada 'politikus akademis' mampu dan mau untuk di-revitalisasi atau di-reformasi agar tercapai pemodelan manusia-manusia yang transformatif? ${ }^{21}$ Padahal kunci

21 Jangankan untuk direvitalisasi hingga menuju reformasi, untuk dievaluasi saja susah. Dan hal ini bukan hanya terjadi di Indonesia saja bahkan sama halnya di luar negeri sejak dulu. Perbedaannya mungkin hanya pada tingkat resistensinya saja. Sebagaimana yang dinyatakan oleh Marx (1990) dalam Speight (2015, hal. 154) bahwa "usaha yang bersifat korektif semestinya dilakukan secara berkala tiap tahun atau tiap semester, akan tetapi persoalan evaluasi terhadap 


\section{Jurnal Ilmiah Sustainable}

Vo. 1. No. 1, Juni 2018, 119-145

sukses untuk proses terlahir kembali atau regenerasi Tri Dharma membutuhkan persilangan sel-sel kehidupan alias pemuncah perkawinan antar kualitas pribadi yang pada klimaksnya mampu memproduksi para pelanjut cita-cita yang lebih bertenaga, kuat dan hebat untuk mencapai tujuan yang benar-benar optimal dalam mereformasi Pendidikan Tinggi di Nusantara di tengah-tengah arus motivasi antar kepentingan baik di tingkat lokal, nasional hingga internasional.

Disinilah esensinya, perguruan tinggi memang tidak bisa kerja sendirian namun harus saling mengisi dan menutupi dalam mengembangkan Pendidikan Tinggi. Mulai dari lembaga legislatif dan eksekutif hingga institusi-institusi edukatif bahkan seluruh masyarakat secara luas harus senantiasa mereformasi dan me-restorasi hingga mengawasi segala kebijakan, pengelolaan dan penyelenggaraan Tri Dharma perguruan tinggi dalam negeri untuk membenahi Sumber Daya Manusia-nya agar menjadi lebih kuat, baik yang sekarang maupun untuk yang akan datang. Optimalnya, memang tidak perlu merubah segalanya hingga berganti wajah dan perangainya namun yang penting bagaimana menatanya kembali dan menyesuaikannya dengan tuntutan dan kebutuhan zaman milenia dan zaman-zaman selanjutnya dengan seribu satu macam istilah agar Pendidikan Tinggi dalam negeri tetap mampu berkembang dan berjalan secara normal.

\section{Regenerasi Interpreter dan Inovator Tri Dharma Perguruan Tinggi}

Diantara tujuan besar pengimplementasian Tri Dharma perguruan tinggi adalah untuk mencerdaskan dan 'membahagiakan' masyarakat. Dan sebagai pengguna langsung Tri Dharma perguruan tinggi khususnya pada aspek pendidikan dan pengajaran serta penelitian, kalangan mahasiswa tentunya harus menjadi salah satu komponen penggiat kreatifitas dan inovasi Tri Dharma.

\footnotetext{
kalangan akademisi kampus, khususnya para professor, telah menjadi semacam isu yang sensitif dan tak mengenakkan selama beberapa tahun bahkan beberapa dekade belakangan dan tentunya hal tersebut sudah sepantasnya untuk diperhatikan dengan serius bagaimana mengatasi resiko munculnya kemarahan sejumlah akademisi tersebut sebab hal itu berpengaruh bagi sistem pendidikan di masa yang akan datang. Namun, sekalipun sulit, usaha evaluasi khususnya yang berkenaan dengan efektifitas kerja mereka merupakan hal yang penting selama dilakukan dengan penuh keseriusan, bermanfaat dan bertujuan yang jelas."
} 


\section{Jurnal Ilmiah Sustainable}

Vo. 1. No. 1, Juni 2018, 119-145

Kegiatan kreatifitas dan inovasi yang dimaksud yaitu implementasi keilmuan dan keahlian 'kekinian' yang telah mereka peroleh yang dapat digunakan untuk melayani masyarakat dalam kegiatan pengabdian baik ketika mereka menjadi mahasiswa ataupun setelah menjadi sarjana.

Berkembang atau tidaknya revitalisasi Tri Dharma pada satu perguruan tinggi terlihat indikatornya, salah satunya, dari keaktifan mahasiswanya. Dan perguruan tinggi mesti meregenerasi para interpreter dan inovator Tri Dharma yang berciri khas ke-Indonesiaan kepada para penerus selanjutnya agar tujuan mulia, alami dan ilmiahnya tercapai baik yang berdasarkan motif-motif pribadi yang bersifat intelektual, emosional dan spiritual hingga kepada motif sosial dan global bahkan motif-motif yang super luas yang bersifat universal. Jikalau dasar pertimbangan 'revitalisasi' mengabaikan program regenerasi jangka panjang untuk anak-cucu berikutnya sebagai pelanjut cerita dan cita-cita Pendidikan Tinggi masa depan maka besar sekali kesalahan dan dosa yang harus kita pikul kedepannya sebab tujuan Pendidikan Tinggi adalah untuk menciptakan generasi penerus yang cerdas bukan hanya intelektualnya saja namun juga emosional dan berikut spiritualnya agar cerdas 'nurani kemanusiannya' dalam berinovasi dan berkreasi dalam mengelola sumber-sumber penghidupan yang terpendam dan tersebar di negeri khatulistiwa yang bercirikan Nusantara untuk kesejahteraan dan kemakmuran seluruh rakyat Indonesia dengan dasar-dasar kebijakan kemanusiaan yang adil dan beradab.

Keberlanjutan inovasi Tri Dharma perguruan tinggi tentunya bukan hanya untuk satu atau dua generasi saja, apalagi hanya untuk generasi saat ini saja. jika agenda globalisasi Pendidikan Tinggi lebih berfokus pada 'sistem pengajaran dan penelitian' saja, maka bangsa ini harus menyusuri kembali peta-peta pengabdian yang hanya diberikan porsi sebesar $10 \%$ pada ruang gerak Tri Dharma agar bisa menjadi lebih besar lagi dengan penguatan-penguatan secukupnya. Jadikan mereka (mahasiswa) sebagai generasi yang 'cinta pengabdian' sebagai bukti syukurnya terhadap segala anugerah dari sang Maha Penciptanya.

Saat ini boleh jadi kita-suka ataupun tidak suka-memang lebih diposisikan sebagai penonton, pengekor dan penikmat kemajuan globalisasi pendidikan Tinggi ketimbang sebagai penggagas dan penggerak utamanya. Namun tugas kita untuk membentuk generasi ilmiah masa depan-disamping tetap menjalin kerjasama dengan dunia internasional-yang mampu bersikap dan berlaku baik 


\section{Jurnal Ilmiah Sustainable}

Vo. 1. No. 1, Juni 2018, 119-145

kepada sesama saudara dan sahabatnya yang sebangsa dan setanah air. ${ }^{22}$ Mereka harus diyakinkan bahwa disinilah tanah tumpah darah mereka sejak jaman nenek moyang dahulu kala. Oleh sebab itu, maka mereka harus senantiasa ditanamkan nilai-nilai kecintaan terhadap keunikan alam dan keberagaman bangsanya. ${ }^{23}$ Merekalah para akademisi masa depan yang diharapakan mampu memberikan penafsiran-penafsiran vital seputar Tri Dharma perguruan tinggi yang implementatif bagi rakyat Indonesia yang sebagian besarnya berada dalam posisi terpinggirkan. ${ }^{24}$ Oleh sebab itu, jika bangsa asing-sebagai ciri khasnya-lebih mendewa-dewakan 'globalisasi sistem Pendidikan dan Risetnya' yang agak berbau kapitalisme, maka tugas kita adalah menjadikan Pendidikan Tinggi bangsa ini yang lebih bercirikan Pendidikan Tinggi yang meninggikan martabat dan bangsanya melalui perhatian dan kepedulian dalam pelayanan dan pengabdian masyarakat.

\section{E. Kesimpulan}

Bagaimanapun juga revitalisasi Pendidikan Tinggi memang tetap harus dilakukan. Apapun dan bagaimanapun pemaknaannya, bahkan seberapa kuat frekuensi desakannya hingga sebesar apapun kemampuan kita, namun satu yang

22 Secara sadar maupun tidak sadar, salah satu dampak globalisasi telah memunculkan pengkaburan nilai dan semangat nasionalisme serta patriotisme. Meskipun demikian, sebagaimana yang dinyatakan oleh Lawson \& Scott (2002) dalam Rapoport (2011, hal. 11) bahwa "hingga kini, minimal masih terdapat satu aspek kewarganegaraan yang secara umum masih diakui oleh hampir seluruh bangsa di dunia yaitu keterkaitan individu dengan bangsa dan negaranya dimana bangunan identitas dan loyalitas kebangsaan bersama telah menjadi inti dalam pendidikan kewarganegaraan mereka." Oleh sebab itu, menurut Rapoport (2011, hal. 11) bahwa "seorang warga negara yang bersangkutan diamanahi sejumlah tanggungjawab kepada bangsa dan negaranya termasuk juga kepada anggota masyarakat lainnya sembari menikmati hak-hak individualnya yang diterima dari negaranya sebagai kompensasi atas jasa-jasanya."

23 Maknai 'cinta' dalam arti yang luas. Salah satu bukti 'cinta' kita kepada dunia Pendidikan Tinggi bangsa ini adalah dengan memperkuat harmonisasi dan kontinuitas Sumber Daya Alam dan Sumber Daya Manusianya. Dengan kekuatan energi 'cinta' itu kita selalu berusaha untuk memberi perhatian dan kepedulian yang sungguh-sungguh dalam menjaga, memelihara, dan menyelamatkan generasi penerus bangsa dan negara ini melalui aktifitas Tri Dharma perguruan tinggi.

${ }^{24}$ Sudah sepantasnya jika yang menjadi fokus kegiatan Tri Dharma lebih tertuju kepada kepentingan masyarakat Indonesia, bukan hanya masyarakat kampus saja-apalagi hanya untuk memfasilitasi kepentingan warga asing (dalam bentuk globalisasi) semata-namun juga seluruh rakyat Indonesia dari Sabang hingga Merauke. Bukankah demikian amanat Pancasila dan UUD 1945? Apakah tujuan tersebut bertentangan dengan perintah Sang Maha Pencipta? 


\section{Jurnal Ilmiah Sustainable}

Vo. 1. No. 1, Juni 2018, 119-145

pasti bahwa revitalisasi Pendidikan Tinggi harus lebih berorientasi 'kemanusiaan' selain orientasi akademis, profesi dan vokasi, hingga orientasi politis dan ekonomis yang bukan melulu mengekori arah pergerakan kepentingan 'politisasi global.' Terlepas dari semua bentuk desakan globalisasi ekonomi dan sosial maupun era industri yang sedang menggurita saat ini, energi penggerak revitalisasi Tri Dharma Perguruan Tinggi beserta segala komponen pendukungnya harus tetap sesuai dengan tujuan pokok, karakter dan keunikan bangsa kita sendiri sebagaimana yang tertuang dalam UUD 1945, Pancasila, GBHN, UU beserta regulasi-regulasi turunannya agar Pendidikan Tinggi kita tetap eksis dengan cita rasa Nusantara dan jati diri ke-Indonesiaannya yang berBhinneka Tunggal Ika yang melintasi laut dan menjangkau antar pulau dengan semangat cinta tanah air dalam ikatan persatuan dan kesatuan bangsa.

Kedepannya, jangan sampai Pendidikan Tinggi kita menjadi sasana pergumulan antar motivasi dan kepentingan asing yang boleh jadi tidak akomodatif dan kooperatif sehingga lupa dengan keaslian visi dan misi negerinya sendiri yang akhirnya membuka kesempatan dan celah pembenaran bagi aktoraktor intelektual global untuk memanfaatkan Sumber Daya baik manusianya maupun alamnya yang terabaikan bagaikan tanah garapan yang tak bertuan yang akan menjadi mangsa liberasi ekonomi dan globalisasi industri pendidikan yang berkedok 'Internasionalisasi Pendidikan Tinggi' yang saling menguntungkan padahal sebaliknya.

Apapun alasannya, apakah karena 'defleksi' energi alamiah globalisasi yang mulanya hanya menuntut perubahan ekonomi dan sosial ataukah karena rengekan paksa dari para generasi penerus bangsa untuk mempersiapkan Pendidikan Tinggi yang lebih baik dan berkualitas di masa depan, revitalisasi tetap saja harus bergerak dan terus bergerilya, baik secara alami maupun ilmiah dengan teknik, strategi dan pendekatan-pendekatan yang simpel dan praktis. Dan jika memungkinkan tidak perlu mengorbankan harta benda milik rakyat secara berlebihan sebab hakikatnya yang harus menjadi fokus utama untuk direvitalisasi itu adalah manusianya bukan yang lain. Selebihnya bisa diadaptasi sesuai dengan sejauh mana kekuatan dan daya jangkau revitalisasi itu sendiri.

Akhirnya, dari kesemua komponen dalam proses revitalisasi pengelolaan dan penyelenggaraan Perguruan Tinggi yang terangkum dalam Tri Dharma Perguruan Tinggi, komponen utama dalam wujud Sumber Daya Manusia 


\section{Jurnal Ilmiah Sustainable}

Vo. 1. No. 1, Juni 2018, 119-145

tentunya harus diurutkan pada nomor wahid dalam daftar revitalisasi. Para civitas akademika kampus baik itu tenaga pendidik (dosen) maupun kependidikannya, dan juga mahasiswanya, kesemuanya harus di-revitalisasi. Artinya, bukan hanya kualitas para dosen yang di-revitalisasi dan mahasiswanya di-regenerasi, akan tetapi para staff kependidikannya juga harus sering-sering direstorasi. Namun lebih dari itu, alangkah hebatnya lagi-memang nampak kedengaran aneh-jika segenap tenaga kependidikan pendukung lainnya-biasa disebut karyawan dan sejenisnya-semisal para satpam dan 'OB' (Office Boy) juga disekolahkan agar mereka lebih tercerahkan sesuai dengan keahlian dan perannya masing-masing agar pelayanan kampus bisa menjadi lebih baik dan prima ke depannya. Namun jika mereka mampu me-revitalisasi diri mereka sendiri secara mandiri tentu hal itu akan menjadi satu prestasi yang spesial yang perlu diacungi dua jempol tangan plus dua jempol kaki. Oleh sebab itu, yang paling utama dan pertama yang harus di-revitalisasi adalah manusianya. Jika sumber daya manusianya sudah di-revitalisasi, maka yang lainnya akan ikut terevitalisasi dengan sendirinya karena energi ikutannya berupa kesadaran dan ketulusan pribadi sangat berpotensi memproduksi etos kerja yang lebih bertenaga dalam menggenjot efektifitas kerja, kreasi dan inovasi hingga tercapainya reformasi pengelolaan Pendidikan Tinggi dan penyelenggaraan Tri Dharma Perguruan Tinggi yang sesungguhnya hingga mampu beradaptasi dan berkompetisi secara global diantara persimpangan kepentingan antar bangsa.

\section{DAFTAR PUSTAKA}

Barirani A, et al. (2017). Can University Profit from General Purpose Inventions? The case of Canadian Nanotechnology Patens. An International Journal of Technological Forecasting and Social Science. Vol 120, July 2017, p. 271283. Elsevier. Available at https://www.sciencedirect.com/journal/ technological forecasting and social change

DPR RI. Panja Evaluasi Pendidikan Tinggi Komisi X DPR RI (2017-2018). Rapat Dengar Pendapat dengan Jajaran Kemenristekdikti. Retrieved on July 18, 2018 from http://www.dpr.go.id/dokakd/dokumen/pdf

Gueenhuizen, M. \& Soetanto, D. (2015). Getting the Right Balance: University Networks' Influence on Spin-Offs Attraction of Funding for Innovation. The 


\section{Jurnal Ilmiah Sustainable}

Vo. 1. No. 1, Juni 2018, 119-145

Journal of Technovation. Vol 36-37, February-March 2015, p. 26-38. Elsevier. Available at http://www. sciencedirect.com/journal/ technovation/vol/36-37

http://tengokberita.com/cambridge-university-akan-buka-cabang-di-indonesiatahun-ini /30 Januari/2018

https://www.kaskus.co.id/thread/5a7d0937c1d770636d8b4567/yuk-intip-profil-

kampus-asing-yang-bakal-masuk-indonesia/

http://perpustakaan.bappenas.go.id/lontar/file?file=digital/blob/F19204/univers itas/asing/dapat/diri/kan/kampus di Indonesia.htm

https://beritagar.id/artikel/berita/pro-kontra-rencana-beroperasinya-

universitas-asing

https://beritagar.id/artikel/berita/pancing-inovasi-jokowi-bisa-kasih-izin-

kampus-asing

Kemenristekdikti. Penyelenggaraan Pendidikan Tinggi dan Pengelolaan Perguruan Tinggi. Retrieved on June, 28, 2018 from http://kelembagaan.ristekdikti.go.id/wp-

content/uploads/2016/04/Penyelenggaraan-Dikti-dan-Pengelolaan-PT.pdf

Luijten-Lub, A. (2007). Choices in Internationalisation: How Higher Education Institutions Respond to Internationalisation, Europeanisation and Globalisation. Czech Republik. CHEPS/UT, Postbus 217, 7500 AE Enschede

Lukens-Bull. A. R. (2013). Islamic Higher Education in Indonesia: Continuity and Conflict. United State. New York. Palgrave Macmillan

Longden, B. (2011). University Ranking: Reliability, Consistency and Validity in Teichler, U. et al. [eds]. University Rankings: Theoretical Basis, Methodology and Impacts on Global Higher Education; The Changing Academy-The Changing Academic Profession in International Comparative Perspective, Part 3. London \& New York. Springer Dordrecht Heidelberg

Ledger, S. et al. (2014). Global to Local Curriculum Policy Processes: The Enactment of the International Baccalaureate in Remote International Schools. Switzerland. Springer International Publishing

Mirowski, P. \& Van Horn, R. (2005). The Contract Research Organization and the Commercialization of Scientific Research. The Journal of Social Studies of Science. Vol. 35, Issue 4, August 2005. Available at http://journals.sagepub.com/toc/sssb/35/4 


\section{Jurnal Ilmiah Sustainable}

Vo. 1. No. 1, Juni 2018, 119-145

Maringe, F. \& Foskett, N. (2010). [eds \& conts]. Globalization and Internationalization in Higher Education: Theoretical, Strategic dan Management Management Perspectives. United Kingdom. London: Continuum International Publishing Group

Menteri Riset, Teknologi, dan Pendidikan Tinggi. Sambutan Hardiknas pada Upacara Peringatan Hari Pendidikan Nasional Tahun 2017. Retrieved on July 18, 2018 from http://www.kopertis12.or.id/wp-content/uploads/ 2017/04/sambutan-hardiknas-2017.pdf

OECD/Asian Development Bank (2015). Education in Indonesia: Rising to the Challenge. OECD Publishing, Paris. Retrieved on July 27, 2018 from http://dx.doi.org/10.1787/9789264230750-en

PP Republik Indonesia Nomor 4 Tahun 2014 tentang Penyelenggaraan Pendidikan Tinggi dan Pengelolaan Perguruan Tinggi. Retrieved on July 18, 2018 from https://isi-ska.ac.id/pengumuman/wp-content/uploads/ 2015/03/PP/No.4/2014.pdf

Permen Ristek Dikti Nomor 55 Tahun 2017: Perguruan Tinggi. Retrieved on June, 28, 2018 http://bsnp-indonesia.org/wp-content/uploads/2017/09/ permenristekdikti-nomor-55-tahun-2017.pdf

Rapoport, A. "Challenges and Opportunities: Resocialization as a Framework for Global Citizenship" in Zajda, J. (2015). (ed.). Globalization, Ideology and Politics of Education Reforms. Switzerland. Education Springer

Speight, G. James. (2015). Educating Scientists and Engineers for Academic \& Non-Academic Career Success. London \& New York. CRC Press. Taylor \& Francis Group

Undang-Undang Republik Indonesia Nomor 12 Tahun 2012 tentang Pendidikan Tinggi. Retrieved on June, 2018 from http://diktis.kemenag.go.id/ prodi/dokumen/UU-Nomor-12-Tahun-2012-ttg-Pendidikan-Tinggi.pdf

Wong, S. M. \& Wu, F. S. Internationalization of Higher Education in East Asia: Issues, Implication and Inquiries in Palmer, D. J, et al, (eds.), (2011). The Internationalization of East Asian Higher Education: Globalization's Impact. United State of America. Palgrave MacMillan.

Zajda, J. (2015). Globalisation, Ideology and Politics of Education Reforms dalam Zajda, J. (2015). (ed.). Globalization, Ideology and Politics of Education Reforms. Switzerland. Education Springer. 